\title{
The Evaluation of Limit of Superior Repositioning of Maxilla in Le Fort I Osteotomy: A 3D Pilot Study
}

\author{
Nesrin Saruhan ${ }^{1 *}$ and Mehmet Ugurlu ${ }^{2}$ \\ ${ }^{1}$ Department of Oral and Maxillofacial Surgery, Eskisehir Osmangazi University, Turkey \\ ${ }^{2}$ Department of Orthodontics, Eskisehir Osmangazi University Faculty of Dentistry, Eskisehir, Turkey.
}

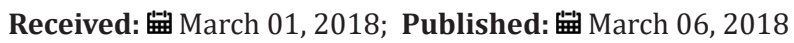

*Corresponding author: Nesrin Saruhan, Department of Oral and Maxillofacial Surgery, Eskisehir Osmangazi University, Turkey

\begin{abstract}
In Le Fort I osteotomies that require superior repositioning of the maxilla, surgeons are confronted with different anatomical problem. The surgeon should consider the condition of the infraorbital foramen and apex of maxillary teeth to determine the best bone resection route. The purpose of this study was to evaluate the limit of superior repositioning of the maxilla in Le Fort I osteotomy by measuring the distance between the apex of the maxillary teeth with the plane between the bilateral infraorbital nerve and the porion. Our study was performed on 74 segments of 37 patients between the ages of 18 and 25 years $(19.21 \pm 1.87$; mean \pm SD). Of these, 50 were male (67.6\%) and 24 were female (32.4\%). The mean distance of the between infraorbital foramen plane and the teeth was $16.95 \pm 3.87 \mathrm{~mm}$ for canines, $20.64 \pm 3.69 \mathrm{~mm}$ for first premolars, $20.53 \pm 4.05 \mathrm{~mm}$ for second premolars, $20.26 \pm 3.56$ for first molars, and $19.79 \pm 3.62 \mathrm{~mm}$ for second molars when genders were evaluated there was no statistically significant difference between canine teeth distance $(\mathrm{p}>0.005)$, but there was a statistically significant difference between premolars and molars $(\mathrm{p}<$ 0.005). When the length of the plane distance were evaluated by the right or left region, there was no difference between the canine, premolar or molar teeth ( $p>0.005)$. According to our results, the vertical height of the infraorbital foramen is a convenient landmark in superior repositioning of the maxilla with Le Fort I osteotomy.
\end{abstract}

\section{Introduction}

Since its introduction in 1867 by Cheevers [1], Le Fort I osteotomy has become an important surgical procedure in the treatment of midfacial deformities. The process was modified by Wassmund in 1927 and standardized by Bell in 1975 [2,3]. It is commonly used to reposition the maxilla for aesthetic and functional purposes [4] and is especially useful in maxillofacial deformities with vertical maxillary excess (such as open bite or long face), dentofacial asymmetries, or malocclusions because it allows for movement in all three planes [5,6]. During this surgical procedure, bilateral bone resection is performed from the aperture priformis to the pterygomaxillary junction to reduce the upper part of the mid face vertical height of the face [2,7]. The bones around the inferior nasal concha, descending palatine artery or infraorbital nerve constitute an obstacle to achieving the planned superior repositioning with the Le Fort I osteotomy [6]. The purpose of this study is to determine the limit of the superior repositioning of the maxilla with the Le Fort I osteotomy by measuring the distance between the apex of the maxillary teeth and the plane between bilateral infraorbital nerve and the porion.

\section{Materials and Methods}

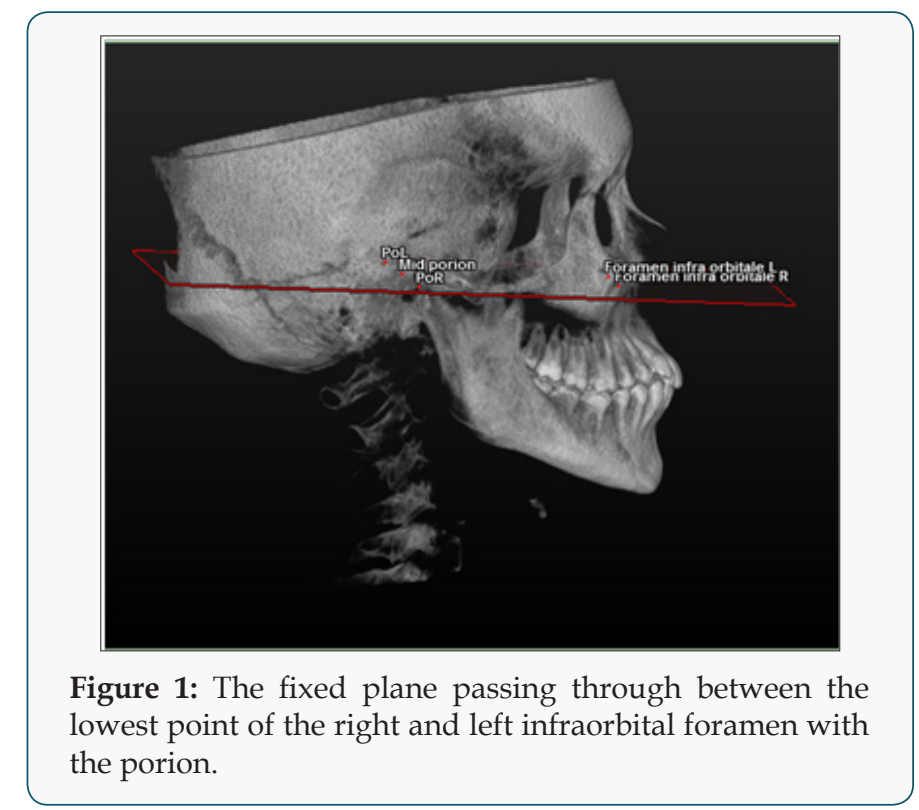


For this study, 37 patients were enrolled who had been referred to the Eskisehir Osmangazi University Faculty of Dentistry in Turkey and required a Cone Beam Computed Tomography (CBCT) examination as part of their routine examination. The CBCT images were obtained in a standing position using the CBCT machine (Planmeca Promax 3D mid, Helsinki, Finland). The exclusion criteria were craniofacial syndrome, presence of a cleft lip or palate, and impacted teeth. On the 3D images of the CBCT data in
Digital Imaging and Communications in Medicine (DICOM) format, a fixed plane passing through the lowest point of the right and left infraorbital foramen with the porion was created using Simplant O\&O dental software (Materialise, Leuven, Belgium) (Figure 1). The determined points were placed by checking the root apexes of the bilateral maxillary canine, premolar, and molar teeth on all three planes (axial, coronal, and sagittal). In multi-rooted teeth, the longest root was taken as reference (Figure 2).
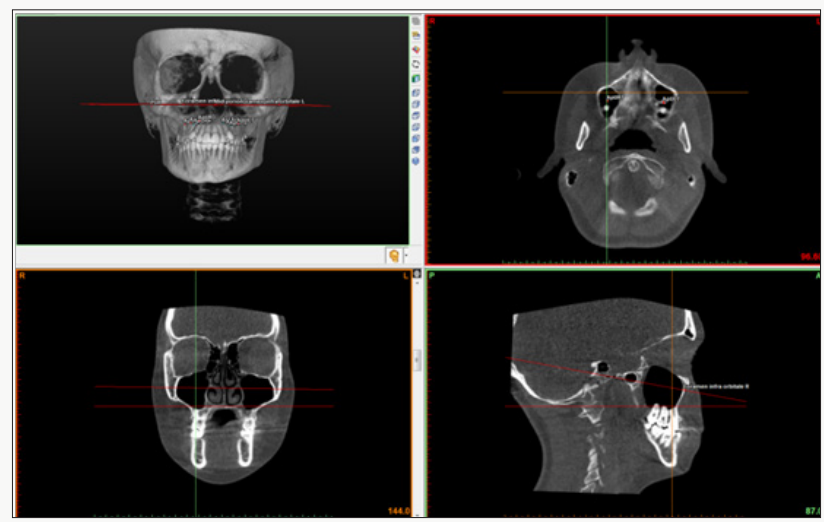

Figure 2: Determination of root apexes and placement of points.

The perpendicular distances between the root apexes and the fixed plane was measured (Figure 3). Statistical analyses were performed using IBM SPSS Statistics 20 package program (Armonk, NY: IBM Corp). A Kolmogorov-Smirnov test was used to evaluate the normality of the data. Descriptive statistics of age, gender, and the perpendicular distances between the root apexes and the fixed plane were performed. The differences according to genders were analyzed with independent t-tests, and the right and left sides of the patients were compared using a paired samples test. In our evaluations, statistical significance was set at $\mathrm{p}<0.05$.

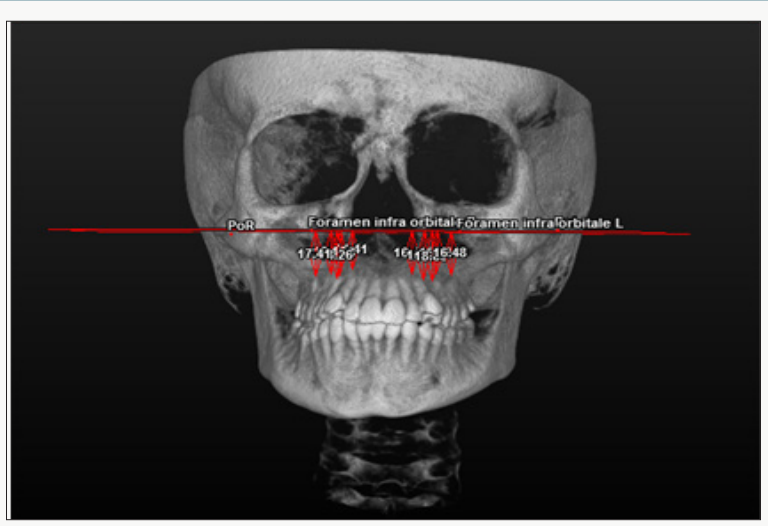

Figure 3: The perpendicular distance between the root apexes and fixed plane.

\section{Results}

Our study was performed on 74 segments of 37 patients between the ages of 18 and $25(19.21 \pm 1.87$; mean \pm SD). Of those, 50 were men $(67.6 \%)$ and 24 were women $(32.4 \%)$. The ages of the women were between 18 and 24 years of age (19.58 \pm 1.79$)$, and the ages of the men were between 18 and 25 years of age (19.04 \pm 1.9 ). The distance between fixed plane and the teeth was seen in Table 1. When comparative statistics were performed according to gender, no statistically significant difference was detected for canine distances $(p>0.05)$ but a statistically significant difference was detected for premolars and molars $(p<0.05)$ (Table 2). When the right and left maxillary region were evaluated, no statistically significant differences were detected ( $\mathrm{p}>0.05$ ) (Table 3).

Table 1: Descriptive statistics including sample size $(\mathrm{N})$, minimum length, maximum length, mean, and standard deviation (SD).

\begin{tabular}{|c|c|c|c|c|c|}
\hline & N & Min. & Max. & Mean & SD \\
\hline Canine & 74 & 8.75 & 27.18 & 16.95 & 3.87 \\
\hline First Premolar & 74 & 14.39 & 30.01 & 20.64 & 3.69 \\
\hline Second Premolar & 74 & 14.37 & 31.64 & 20.53 & 4.05 \\
\hline First Molar & 74 & 14.07 & 29.01 & 20.26 & 3.56 \\
\hline Second Molar & 74 & 14.25 & 29.11 & 19.79 & 3.62 \\
\hline
\end{tabular}


Table 2: Comparative statistics according to gender.

\begin{tabular}{|c|c|c|c|c|c|c|c|}
\hline & Gender & N & Min. & Max. & Mean & SD. & p \\
\hline \multirow{3}{*}{ Canine } & Female & 24 & 12.16 & 19.96 & 16.36 & 2.13 & 0.266 \\
\cline { 2 - 8 } & Male & 50 & 8.75 & 27.18 & 17.23 & 4.47 & 2.25 \\
\hline \multirow{3}{*}{ First Premolar } & Female & 24 & 14.72 & 22.15 & 18.95 & $0.006^{*}$ \\
\cline { 2 - 8 } & Male & 50 & 14.39 & 30.01 & 21.45 & 3.98 & 2.35 \\
\hline \multirow{2}{*}{$\begin{array}{c}\text { Second } \\
\text { Premolar }\end{array}$} & Female & 24 & 14.79 & 21.87 & 18.56 & $0.003^{*}$ \\
\hline \multirow{3}{*}{ First Molar } & Male & 50 & 14.37 & 31.64 & 21.47 & 4.36 & 2.22 \\
\cline { 2 - 8 } & Female & 24 & 15.53 & 24.40 & 18.78 & $2.012^{*}$ \\
\hline \multirow{2}{*}{ Second Molar } & Male & 50 & 14.07 & 29.01 & 20.97 & 3.87 & \\
\cline { 2 - 8 } & Female & 24 & 14.25 & 21.58 & 18.13 & 2.23 & $0.006^{*}$ \\
\hline
\end{tabular}

Table 3: Evaluation of right and left maxillary region in terms of distance.

\begin{tabular}{|c|c|c|c|c|c|c|c|}
\hline & Gender & $\mathbf{N}$ & Min. & Max. & Mean & SD. & $\mathbf{p}$ \\
\hline \multirow{2}{*}{ Canine } & Right & 37 & 11,01 & 26,36 & 16,45 & 2,92 & 0.093 \\
\hline & Left & 37 & 8,75 & 27,18 & 17,45 & 4,63 & \\
\hline \multirow{2}{*}{ First Premolar } & Right & 37 & 14,72 & 29,22 & 20,03 & 2,91 & 0.109 \\
\hline & Left & 37 & 14,39 & 30,01 & 21,26 & 4,29 & \\
\hline \multirow{2}{*}{$\begin{array}{l}\text { Second } \\
\text { Premolar }\end{array}$} & Right & 37 & 14,79 & 30,89 & 19,75 & 3,24 & 0.464 \\
\hline & Left & 37 & 14,37 & 31,64 & 21,30 & 4,64 & \\
\hline \multirow{2}{*}{ First Molar } & Right & 37 & 15,53 & 28,21 & 19,78 & 2,76 & 0.388 \\
\hline & Left & 37 & 14,07 & 29,01 & 20,74 & 4,19 & \\
\hline \multirow{2}{*}{ Second Molar } & Right & 37 & 14,25 & 29,11 & 19,26 & 3,01 & 0.502 \\
\hline & Left & 37 & 14,35 & 28,89 & 20,31 & 4,11 & \\
\hline
\end{tabular}

\section{Discussion}

Le Fort I osteotomy is mostly used for the correction of Class II and Class III dentofacial deformities and is generally associated with only minor postoperative complications $[2,8,9]$. Among these complications, the most frequent are dysesthesia and paraesthesia in both the area innervated by the infraorbital nerve and in the facial and palatal gingiva in the upper jaw $[10,11]$. Also, the most persistent complication after Le Fort I osteotomy seems to be decreased sensory function in the upper teeth $[12,13]$. In this study we aimed to measure the distance between the apex of the maxillary teeth with the plane between the bilateral infraorbital nerve and the porion in this way evaluate the limit of superior repositioning of maxilla with Le Fort I osteotomy thus preventing the complications that may occur in sensory function in the upper teeth. Le Fort I osteotomy is a surgical procedure usually performed on young patients. It has also been reported in the literature that most of the patients are men because of the high prevalence of maxillofacial traumas in men compared to women [14]. In our study, the patients' ages were between 18 and 25 years $(19.21 \pm 1.87)$. The ages of the women were between 18 and $24(19.58 \pm 1.79)$, and the ages of the men were between 18 and 25 (19.04 \pm 1.9$)$.

It has been reported that the most common complication is an impaired sensory function in the maxillary teeth [12-16]. The reported incidence of postoperative changes in Le Fort I osteotomy sensitivity varies from $9 \%$ to $85 \%[10,17]$, and somatosensory disturbance has been reported in $64 \%$ of patients in another study [18]. This often depends on whether the maxilla becomes segmented during the procedure and on the level of the osteotomy line. Generally, surgeons use a simple ratio between the height of the crown, which is as high as half the length of the roots, to prevent damage to the molar roots during osteotomy $[10,18]$. In this study, we aimed to find a more concrete value of the distance from the apex of the teeth to the infraorbital formamen plane in case of maxillary superior repositioning with Le Fort I osteotomy. The infraorbital foramen is an obstacle to the superior repositioning of the maxilla with Le Fort I osteotomy [6]. The height of the infraorbital foramen is symmetrical, so the vertical length of infraorbital foramen from the alveolar bone can be used as a consistent landmark during Le Fort I osteotomy [14,19].

Preoperative planning is very important to ensure a safe route bone resection. Therefore, the validity of the vertical height of the infraorbital foramen should be confirmed [14]. For this reason, the infraorbital foramen was used as a landmark in our study. Bendriem et al. [14] reported that the height of the root of the first and second molar teeth was $11.71 \pm 1.83 \mathrm{~mm}$ and the height of the canine root was $17.11 \pm 2.60 \mathrm{~mm}$. In the vertical plane, the height of infraorbital foramen from the maxillary alveolar bone was 33.95 
$\pm 3.22 \mathrm{~mm}$ on the right and $34.28 \pm 3.17 \mathrm{~mm}$ on the left. There was no statistically significant difference between these lengths. They reported that a $15 \mathrm{~mm}$ bone resection could be made in the canine area and a $20 \mathrm{~mm}$ bone resection in the molar area.

There is also no risk of infraorbital pedicle injury if the section passes less than $30 \mathrm{~mm}$ from the alveolar border. When the distances between the infraorbital foramen plane and the apex of the root were evaluated, there was no statistically significant difference between the right and left maxillary region in our study. The shortest distances were found in the canine region, followed by the second molar, first molar, second premolar and first premolar in order of increasing distance. But we suggest that the bone resection must be performed $13 \mathrm{~mm}$ above the alveolar border in canine area and $16 \mathrm{~mm}$ above the alveolar border in molar area and in areas where the section passes less than $30 \mathrm{~mm}$ from the alveolar border. When evaluated in terms of gender, no statistically significant difference was found between canine ( $p>0.005)$ but the distance was significantly greater in men than in women for premolars and molars ( $\mathrm{p}<0.005)$.

\section{Conclusion}

Considering the proximity of the infraorbital foramen and length of root apex, we achieved the highest superior repositioning of $13 \mathrm{~mm}$ in the canine region and $16 \mathrm{~mm}$ in the molar region using Le Fort I osteotomy with the planned superior repositioning of maxilla. Le Fort I osteotomy should be combined with different osteotomies if more than $13 \mathrm{~mm}$ of superior repositioning of the maxilla is planned.

\section{Data Availability}

The data used to support the findings of this study were provided by corresponding author under license, and so cannot be made freely available. Access to these data will be considered by the author upon request, with permission of corresponding author.

\section{Acknowledgement}

The author thanks to Dr. Ilhan Metin DAGSUYU for the great assistance on using of the Simplant O\&O programme.

\section{References}

1. Moloney F, P Worthington (1981) The origin of the Le Fort I maxillary osteotomy: Cheever's operation. Journal of oral surgery 39(10): 731734.

2. Bell WH (1975) Le Forte I osteotomy for correction of maxillary deformities. Journal of oral surgery 33(6): 412-426.

3. Erbe M, Lehotay M, Göde U, Wigand ME, Neukam FW (2001) Nasal airway changes after Le Fort I-impaction and advancement: anatomical and functional findings. International Journal of oral and maxillofacial surgery $30(2): 123-129$

4. Sandor GK, Charles DA, Lawson VG, Tator CH (1990) Trans oral ap- proach to the nasopharynx and clivus using the Le Fort I osteotomy with midpalatal split. International journal of oral and maxillofacial surgery 19(6): 352-355.

5. Bell WH, TD Creekmore, RG Alexander (1977) Surgical correction of the long face syndrome. American Journal of orthodontics 71(1): 40-67.

6. Yoshioka I, Khanal A, Kodama M, Furuta N, Tominaga K (2009) Postoperative skeletal stability and accuracy of a new combined Le Fort I and horseshoe osteotomy for superior repositioning of the maxilla. International Journal of oral and maxillofacial surgery 38(12): 1250-1255.

7. Bell WH (1973) Biologic basis for maxillary osteotomies. American Journal of physical anthropology 38(2): 279-289.

8. Epker BN, SA Schendel (1980) Total maxillary surgery. International Journal of oral surgery 9(1): 1-24.

9. Fish LC, BN Epker, CR Sullivan (1993) Orthognathic surgery: the correction of dentofacial deformities. Journal of oral and maxillofacial surgery: official journal of the American Association of Oral and Maxillofacial Surgeons 51(1 Suppl 1): 28-41.

10. Rosenberg A, HF Sailer (1994) A prospective study on changes in the sensibility of the oral mucosa and the mucosa of the upper lip after Le Fort I osteotomy. Journal of cranio-maxillo-facial surgery: official publication of the European Association for Cranio-Maxillo-Facial Surgery 22(5): 286-293.

11. Al Din OF, KM Coghlan, P Magennis (1996) Sensory nerve disturbance following Le Fort I osteotomy. International Journal of oral and maxillofacial surgery 25(1): 13-19.

12. Ellingsen RH, J Artun (1993) Pulpal response to orthognathic surgery: A long-term radiographic study. American journal of orthodontics and dentofacial orthopedics: official publication of the American Association of Orthodontists, its constituent societies, and the American Board of Orthodontics 103(4): 338-343.

13. Justus T, Chang BL, Bloomquist D, Ramsay DS (2001) Human gingival and pulpal blood flow during healing after Le Fort I osteotomy. Journal of oral and maxillofacial surgery: official journal of the American Association of Oral and Maxillofacial Surgeons 59(1): 2-7; discussion 7-8.

14. Bendrihem R, Vacher C, Fohlen A, Pelage JP (2017) Anatomic basis of Le Fort 1 impaction osteotomy: a radiological study. Surgical and radiologic anatomy: SRA 39(11): 1209-1214.

15. De Jongh M, D Barnard, D Birnie (1986) Sensory nerve morbidity following Le Fort I osteotomy. Journal of maxillofacial surgery 14(1): 10-13.

16. Harada K, M Sato, K Omura (2004) Blood-flow and neuro sensory changes in the maxillary dental pulp after differing Le Fort I osteotomies. Oral surgery, oral medicine, oral pathology, oral radiology, and endodontics 97(1): 12-17.

17. Kahnberg KE, L Vannas Lofqvist, G Zellin (2005) Complications associated with segmentation of the maxilla: a retrospective radiographic follow up of 82 patients. International Journal of oral and maxillofacial surgery 34(8): 840-845.

18. Thygesen TH, Bardow A, Norholt SE, Jensen J, Svensson P (2009) Surgical risk factors and maxillary nerve function after Le Fort I osteotomy. Journal of oral and maxillofacial surgery: official journal of the American Association of Oral and Maxillofacial Surgeons 67(3): 528-536.

19. Shimo T, Nishiyama A, Jinno T, Sasaki A (2013) Severe gummy smile with class II malocclusion treated with LeFort I osteotomy combined with horseshoe osteotomy and intraoral vertical ramus osteotomy. Acta medica Okayama 67(1): 55-60. 
This work is licensed under Creative Commons Attribution 4.0 License

To Submit Your Article Click Here:

Submit Article

DOI: 10.32474/MADOHC.2018.01.000117

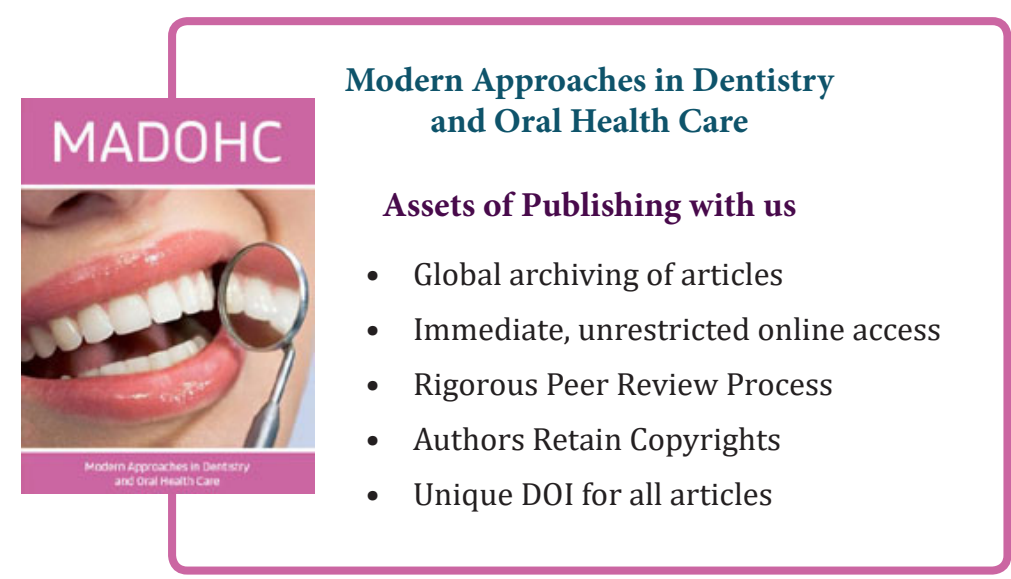

